Article

\title{
Learning Processes in Mechanics of Structures: Allying Analytical and Numerical Approaches
}

\author{
Fábio A. O. Fernandes ${ }^{1}(\mathbb{D})$, Clauber Marques ${ }^{2}$, Jovani Castelan ${ }^{2}\left(\mathbb{D}\right.$, Daniel Fritzen ${ }^{2, *(\mathbb{D})}$ and \\ Ricardo J. Alves de Sousa $1, *$ (D) \\ 1 TEMA-Centre for Mechanical Technology and Automation, Department of Mechanical Engineering, \\ University of Aveiro, Campus de Santiago, 3810-193 Aveiro, Portugal; fabiofernandes@ua.pt \\ 2 SATC University, Rua Pascoal Meller, 73-Bairro Universitário CEP, Criciúma 88805-380, SC, Brazil; \\ clauber.marques@satc.edu.br (C.M.); jovani.castelan@satc.edu.br (J.C.) \\ * Correspondence: daniel.fritzen@satc.edu.br (D.F.); rsousa@ua.pt (R.J.A.d.S.)
}

Received: 23 February 2020; Accepted: 14 April 2020; Published: 20 April 2020

\begin{abstract}
This paper reports pedagogical experiences and educational techniques in the field of Mechanics of Structures (Mechanical Engineering degree), resorting to computational tools. Several aspects are addressed, covering CAD (Computer-Aided Design) modelling systems to CAE (Computer-Aided Engineering) solutions, in terms of analysis and validation of mechanical resistance calculations. Therefore, structural mechanics fundamental concepts and mechanics of materials are also addressed. Particular focus is given on the development of curricula components related to Computer-Aided Design and Manufacturing. Doing so, three-dimensional structural modelling is applied to study the behaviour in selected simple case-studies where an external load is applied and the corresponding deflections are evaluated. Then, analytical and numerical analyses are performed and compared. During classes, patent aversion to solve analytical problems was clearly observed on the part of the students once calculus knowledge was required. The typical trend in engineering students, skipping the manual analytical methodology to solve a problem in order to go straight to numerical simulations via commercial Finite Element (FE) codes, was observed. The main focus of this work is, therefore, to determine the pedagogical effects of allying the analytical procedures and virtual simulators. It was possible to confirm the beneficial aspects of such methodology, considering that the regular engineering student has already a scientific basis on calculus and analytical process. Such knowledge will support mechanical project decisions, from model development to the analysis, and a sounding background to perform criticism of the results provided by the software.
\end{abstract}

Keywords: education; learning; analytical solutions; numerical solutions; CAD/CAE

\section{Introduction}

In the early 1960s, Ivan Sutherland, a doctoral student at the Massachusetts Institute of Technology (MIT), developed the first interactive 2D Computer-Aided Design (CAD) software, named "Sketchpad" [1]. Since then, many pieces of related research were carried out. These type of tools rapidly spread in the field and are currently being used in numerous commercial software packages. This evolution resulted in a great variety of digital tools that directly impacted many professional activities from engineers to designers in product development [2,3].

In the 1980s, commercial CAD systems were developed, such as Autodesk AutoCAD, for 2D drawing, and PTC Pro-Engineer, for 3D modelling. Currently, many other CAD systems are being widely used in engineering, design and manufacturing, including geometric modelling, structural and motion analysis, CNC (computer numerical control) machining and rapid prototyping [4]. 
CAD plays an important role in engineering education since there is a significant interest in learning this technology within universities, as well as in the industry [5]. The common interest is that education should provide base knowledge and expertise for professional activity. According to Ye et al. [6], this is only possible if four requirements are met: the capability to formulate engineering problems; the ability to use a computer in solving engineering problems; solid knowledge about the design and manufacturing processes; and most importantly, practice.

Nowadays, teachers who often deal with CAD software and teach 3D modelling in universities face a problem: the heterogeneity of the class, related to the knowledge of resources and software applications. It is common to have students in the class with solid knowledge and experience in the field, as they work daily with CAD in the development of projects. On the other hand, most students have or have had no contact with such resources. Furthermore, currently, it should be considered that basing classes only on tutorials and the sequential use of resources is not so different from ready-made content on the Internet, since countless websites, blogs, virtual forums and social networks provide the same information, without need for a teacher [7]. As an example to this dilemma, Fritzen and Castelan [8] addressed the application of contextualised CAD/CAM software classes to traditional manufacturing processes in the mechanical industry, presenting the computational resources applied directly to the needs of industrial projects.

In a recent work, Ullah and Harib [9] addressed the issue of educating engineering students with knowledge of and skills in CAD/CAM. However, to solve engineering problems, especially in the field of Mechanical Engineering, knowledge of and skills in CAD/CAM/CAE are of utmost importance. Bravo et al. [10] indicated the importance of such methodology, which gives more responsibility to the students, allowing them to participate more and thus an opportunity to develop creative skills in the area of design and manufacturing engineering.

The fact is that teaching and learning in CAD is not an easy task, as it is not just about computational skills but also the capacity to think about the problem and to solve it, as well as other important factors such as spatial vision and motor coordination. This means that less experienced students or even beginners may face some significant difficulties due to the lack of scientific basis, the need for continuous improvement and rapid obsolescence of acquired knowledge [11]. In both cases-students with and without experience in CAD—-there is a need for more theoretical bases and confidence in the use of simulation tools. Knowledge of fundamental concepts such as spatial geometry, static and resistance of materials is extremely important in the student success in order to achieve the corresponding discipline objectives.

Nowadays, with the currently available technology, it is tempting to avoid the slow, laborious and error-prone analytical calculations and go straight to the computational simulation, usually a faster solution. However, this practice is inadvisable since accurate modelling, from the input data (geometry, material definition, boundary conditions) to necessary simplifications (e.g., symmetries), is fundamental to obtain a reliable solution. Nevertheless, with the rapid development of complex numerical models applied to manufacturing, cultivating students' ability to solve complex engineering problems using the FE method and other numerical calculations becomes more challenging [12-14].

Recently, Guo et al. [12] carried out a project for undergraduate students, where they implemented finite element modelling to enhance students' understanding of theoretical mechanics and to introduce computational methods to undergraduate students at an early stage during their undergraduate education. The students were required to use different methods to analyse the stress state of a typical engineering structure and seek the optimal design (e.g., theoretical calculations). They reported a good feedback from the students, demonstrating how it can increase their interest in learning and applying the acquired knowledge.

Similarly, in this work, it is addressed how important it is to have an engineering background in order to transmit to students the application of FE analysis (FEA) in engineering problems, introducing the engineering reality into the teaching of FEA as stressed out by Guo et al. [12]. In addition, analytical methods make it possible for the student to have a clear understanding of the physical phenomenon, 
gaining competences in both input data and model definition as well as in the interpretation of the results. The solving of the problem is carried by the computer; therefore, a proper definition is of outermost importance. Project errors at this level are of the responsibility of the engineer or designer. Even considering the reliability of computational systems, the model has to be configured correctly, and the professional experience of the user in the issues relevant to the simulated problem is an important resource to be considered. For instance, the constitutive models in commercial codes offer standardised options, not taking into account phenomena such as oxidation. On the other hand, complex problems where millions of finite elements are necessary are obviously unfeasible to be solved analytically. Therefore, a combination of different types of knowledge is necessary, where experience reveals to be a major variable.

Finally, analytical methods develop students' capacity to think and criticise, to support the scientific results and to compare and question the validity of the results from numerical simulations. Yixian et al. [15] indicate that using CAE tools in the classroom can help the student understand advanced processes regarding design, simulation and manufacturing, from a concept. The theoretical knowledge of related concepts makes it possible to easily and quickly understand it.

\section{Methods}

Classes were planned by establishing and prioritising a connection between CAD and CAE tools. Nevertheless, in the first place, the analytical solution is explored and only then the numerical one. The teaching plan was structured in twenty weeks (face to face meetings). They took place at the laboratory of computational mechanics used in the teaching of 3D modelling, structural simulation and also in the simulation of manufacturing processes. The development of this curricular component is related to Computer-Aided Design and Manufacture, which occurs in the seventh semester of Mechanical Engineering Course, offered by Faculty SATC, from Criciúma, Santa Catarina State, Brazil.

The first four meetings are intended for the presentation and development of activities related to visualisation and transformations, which are responsible for the generation and manipulation of the three-dimensional parts generated on the computer screen. The fifth and sixth meetings are intended for presentation of the modelling features. In this step, there is no use of tutorials and learning takes place via intuitive use of basic commands, easy to assimilate.

The next eight meetings are intended for modelling and structural validation of solids (parts and products), through analytical (manual calculations) and numerical calculations (computer simulation). The following two meetings are dedicated to mould generation procedures and manufacturing simulation (machining). Finally, this cycle ends with the elaboration of a collaborative project carried out by teams during the remaining four meetings. This project addresses all content explored in the course, including modelling, selection and definition of material, structural validation, simulation, tooling creation (mould/die), machining simulation and drafting of technical documentation (e.g., drawings). Thus, the amount of content is extensive considering the course load of $60 \mathrm{~h}$, demanding the collaboration and commitment of both teacher and class to achieve the goals set in due time.

\section{Analytical-Numerical Methodologies in the Classroom}

This section presents a problem solved in the classroom during the course of Computer-Aided Design and Manufacturing within the curricula of Mechanical Engineering. The content of this class is based on geometrical and numerical modelling and also analysis of static loading. It is expected that students already have knowledge regarding technical drawing, structural loading, mechanical resistance and basic experience with CAD tools.

In this activity, it is expected that the student is able to interpret and analyse the problem, to model it using CAD tools and to simulate it. The problem consists in determining if a beam has enough strength to support a concentrated static load. Table 1 summarises the different steps planned for the student to solve the structural problem. The factor of safety expresses the load carrying capacity of a 
system beyond what it can actually support, basically, how much stronger it is than it needs to be for specific loading conditions.

Table 1. Steps planned for the student to solve the structural problem.

\begin{tabular}{|c|c|}
\hline Step & Description \\
\hline 1 & $\begin{array}{l}\text { Perform the calculations to determine the reactions, diagrams, stresses, bending moment, maximum } \\
\text { deflection and factor of safety. }\end{array}$ \\
\hline 2 & 3D modelling using CAD tools to set the model for numerical analysis. \\
\hline 3 & $\begin{array}{l}\text { Perform computational simulation by modelling the beam with finite elements, defining the material, } \\
\text { boundary conditions and loads. }\end{array}$ \\
\hline 4 & Compare the values obtained analytically and numerically. \\
\hline 5 & Analyse the results and discuss them (technical report). \\
\hline
\end{tabular}

Structural parts and metal profiles, such as I and U beams, are relatively easy to model. The student sketches the profile and assigns a length for extrusion. Nevertheless, due to the beam's structural function, the simulation of working loads, both static and dynamic, is fundamental to validate a model by determining the type and size of the profile, its layout in the structure and ideal manufacturing material considering safety and financial constraints. Figure 1 depicts the problem presented to the students.

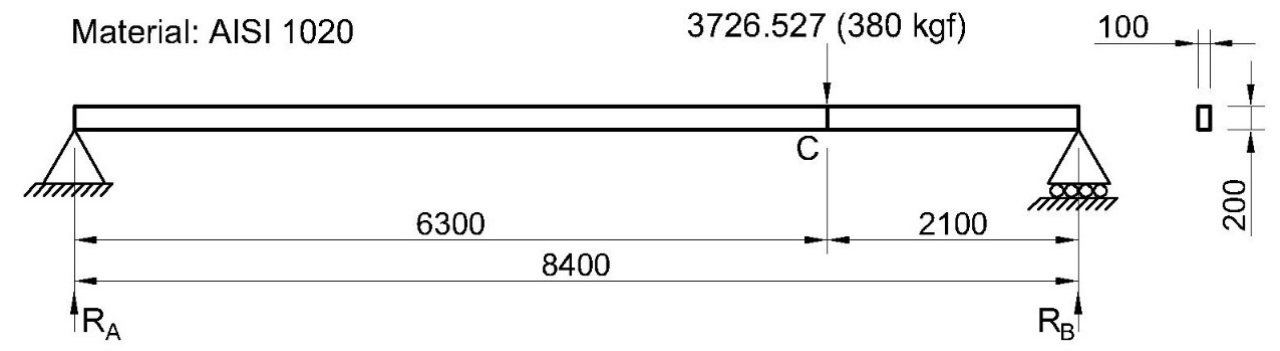

Figure 1. Structural problem presented to the students (dimensions in $\mathrm{mm}$ and load in N).

\section{Results}

\subsection{Analytical Solution}

Generally, the students reach the expected analytical solution. Reaction forces of $931.63 \mathrm{~N}$ and $2794.90 \mathrm{~N}$ were obtained in points $\mathrm{A}$ and B, respectively. Figure 2 presents the shear force and bending moment diagram. A maximum bending moment of 5869.28 N.m was determined. Maximum stress and deflection were of $8.63 \mathrm{MPa}$ and $2.41 \mathrm{~mm}$, respectively. Finally, a factor of safety of 39.94 was determined.

\subsection{Numerical Analysis}

After obtaining the analytical solution, the next step is to generate a 3D CAD model of the product/part to be validated. In this case, as it is about a simple geometry (rectangular section bar), students have no difficulties in performing this step. The software integrated interface (SOLIDWORKS Education Version) allows the student to start the development of the model by defining the material, boundary conditions, loads and most importantly by meshing the component with finite elements. Additionally, it is necessary to define the results necessary for post-processing. Basically, the same parameters used in the analytical solution in order to establish a direct comparison (stresses, displacements, factor of safety, shear force and bending moment diagrams; Figures 3-7, respectively). 

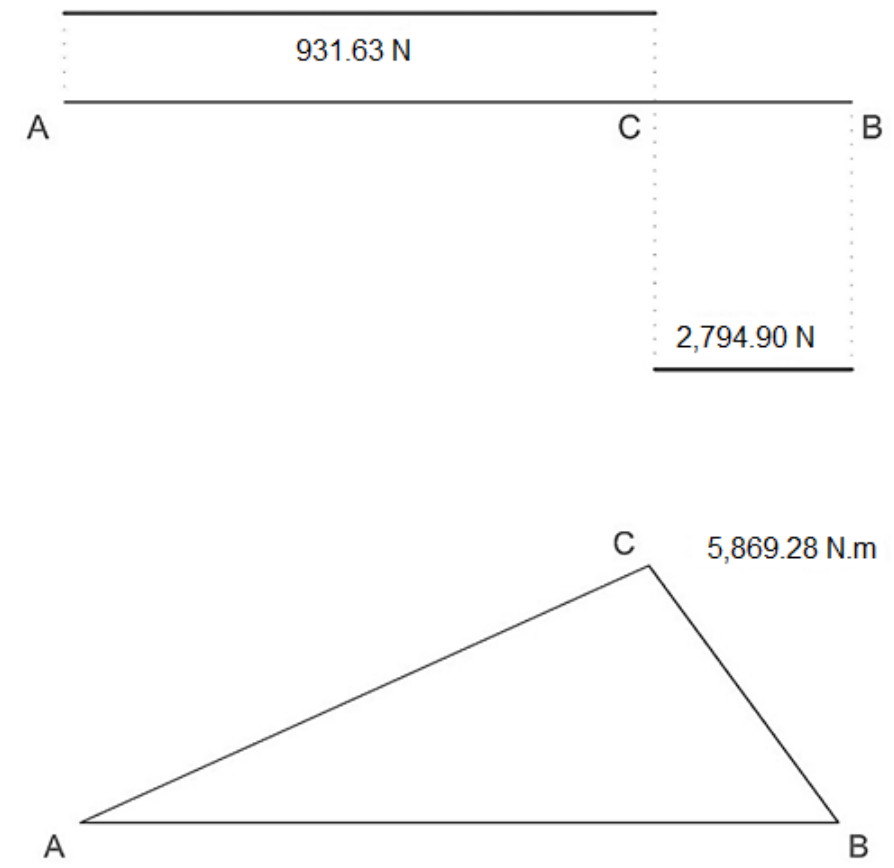

Figure 2. Shear force and bending moment diagram.

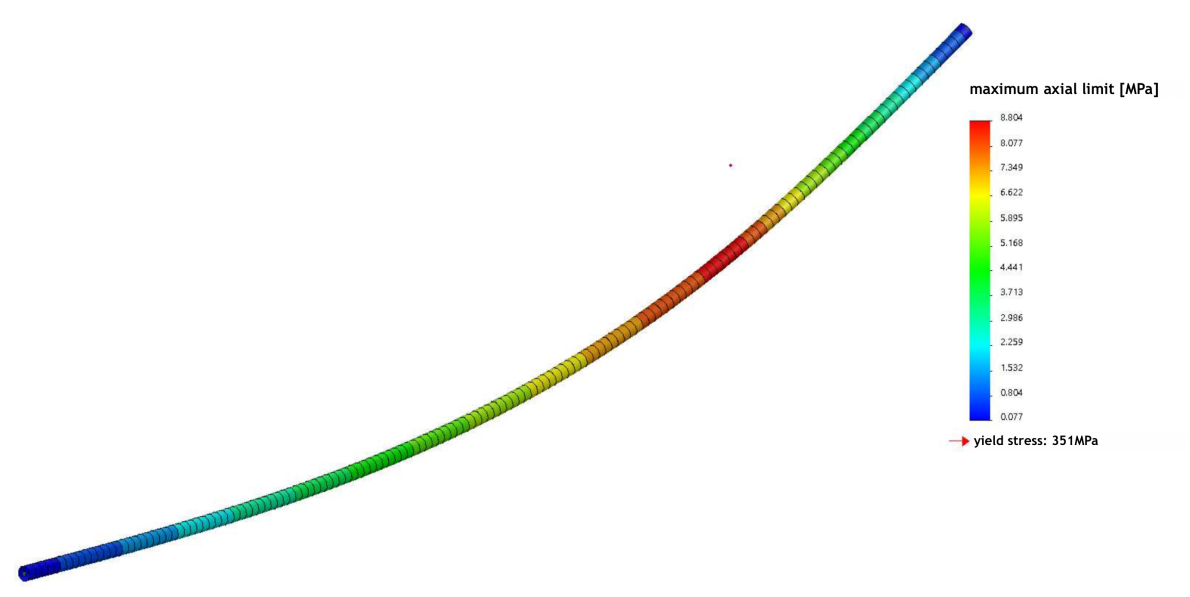

Figure 3. Stress plotting [MPa].

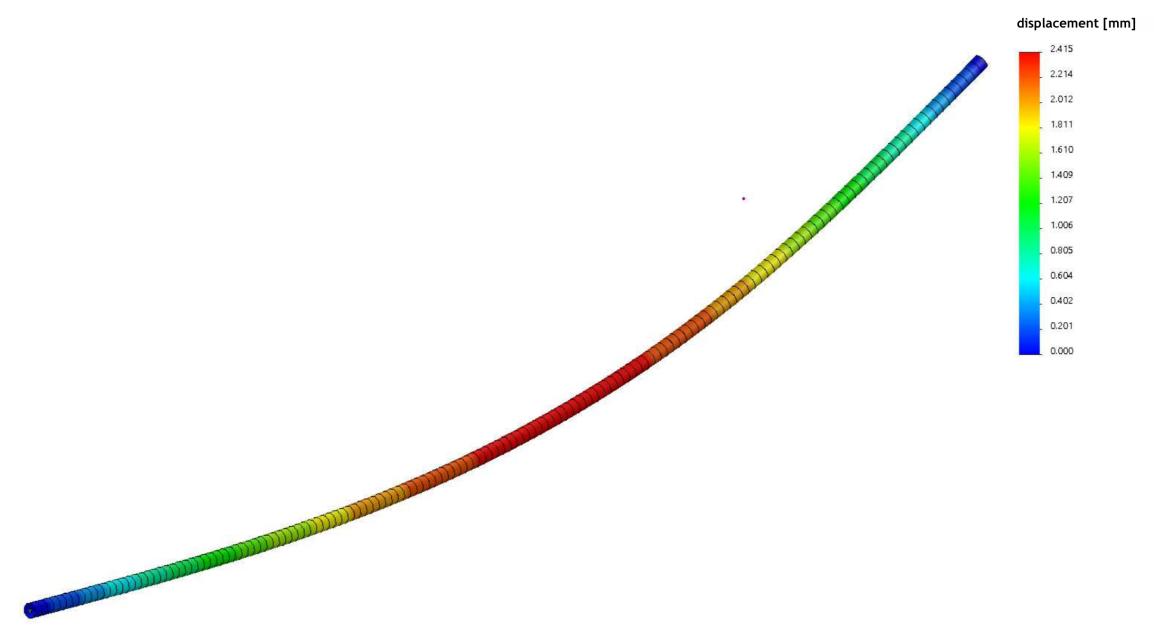

Figure 4. Displacement plotting [mm]. 


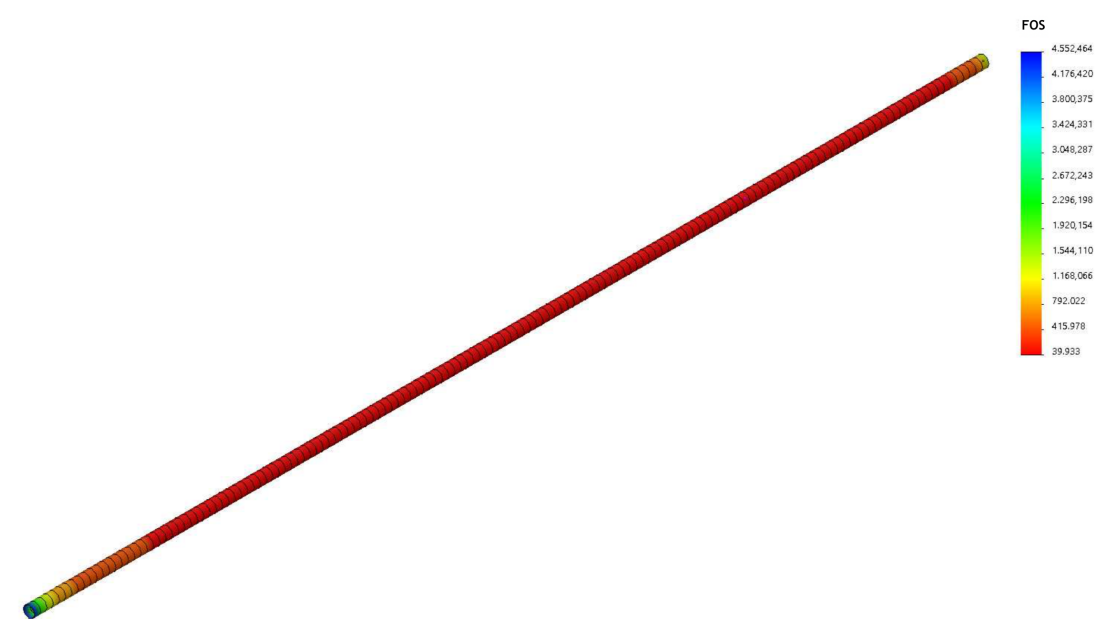

Figure 5. Factor of safety plotting.

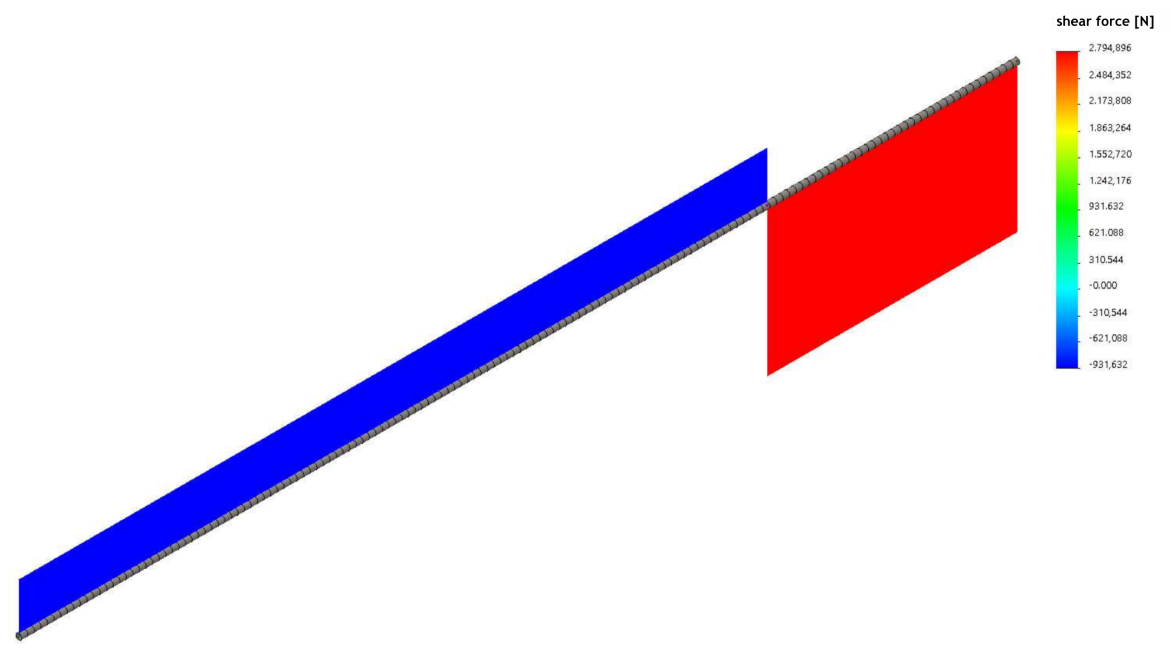

Figure 6. Shear force diagram [N].

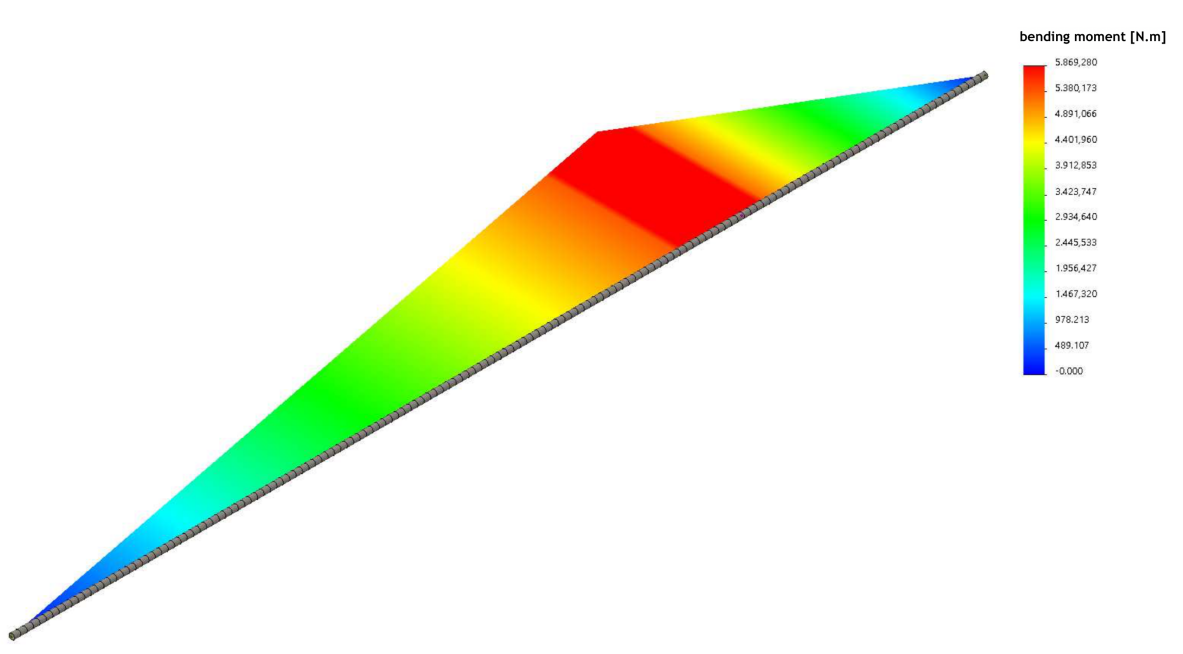

Figure 7. Bending moment diagram [N.m]. 


\subsection{Numerical-Analytical Comparison}

After the computational simulation, students are instructed to compare the results obtained with both methods, to assess the level of similarity or discrepancy of the results. If the latter is verified, both calculations needed to be revised and redone in order to find the error and solve the problem in the right way. The values presented in Table 2 prove the reliability of both procedures.

Table 2. Comparison between analytical and numerical results.

\begin{tabular}{lcc}
\hline Result & Analytical & Numerical \\
\hline Maximum stress [MPa] & 8.63 & 8.80 \\
Maximum deflection [mm] & 2.41 & 2.41 \\
Shear force [N] & $2794.90 I-931.63$ & $2794.90 I-931.63$ \\
Bending moment [N.m] & 5869.28 & 5869.28 \\
Factor of safety & 39.94 & 40 \\
\hline
\end{tabular}

Obtaining similar results using two different methods gives greater confidence and scientific rigour to the employed methodology. Students demonstrate greater trust in interpreting the results because they understand the physical phenomenon.

The role of interdisciplinary work in transferable skills acquisition, as well as their many benefits for all the undergraduate students involved is clear, as reported by [16]. Students will eventually need to seek in other curricular components knowledge learned in previous lectures that may prove necessary for the execution of a given task. Moreover, activities carried out "manually" in any of these curricular components can be supplemented by the computational techniques performed in the presented course.

The active participation of the student occupies most part of the lesson, with the execution of the task in two steps. Working on two-person teams or even larger ones, depending on the complexity and time necessary to complete the activity, fosters collaborative learning and engagement.

The synthesis of the lesson is made comparing the results of the two analyses: when results are coherent, it is concluded that the procedures adopted are correct, validating the activity results. When there is inconsistency, both need to be revised, searching for failure in the solution such as issues with units, wrong material definition, mathematical calculations, mesh convergence not performed, etc.

\section{Conclusions}

The use of different methodologies for solving the presented structural problem makes it possible for the teacher and students to have more tools available to themselves. This increases the efficiency of the cognitive process and boosts the acquired knowledge in a sustained manner. Although each simulation software has its specific settings, the scientific base built with the analytical processes enables the student for a faster and safer adaptation in his future professional activity.

At first, an aversion of students to manual calculations and an instant desire to skip this step and go straight to computational simulation are noticeable. However, when the comparison of results is performed, the students perceive the relationship between scientific theory and the practical result presented by the numerical code. This perception makes the student realise the importance of manual techniques in the development of learning.

Both the analytical-manual and numerical-computational processes, even when performed within the correct procedures, may not indicate an absolute truth. As mentioned above, real situations present complex variables and unusual situations that calculation processes, due to their simplifications, do not consider. The development of knowledge in science involves modelling processes where theory, experiment and computation are dynamically interconnected [17]. It is important that the teacher transmits this reality to the students. For a completely safe analysis, it is necessary to include one additional and final step-the experimental one. 
Author Contributions: Conceptualization, F.A.O.F., C.M., J.C., D.F. and R.J.A.d.S.; methodology, C.M., J.C. and D.F.; software, C.M., J.C. and D.F.; validation, F.A.O.F. and R.J.A.d.S.; formal analysis, F.A.O.F. and R.J.A.d.S.; investigation, C.M., J.C. and D.F.; resources, C.M., J.C. and D.F.; data curation, C.M., J.C. and D.F.; writing-original draft preparation, F.A.O.F., C.M., J.C., D.F. and R.J.A.d.S.; writing-review and editing, F.A.O.F. and R.J.A.d.S.; visualization, F.A.O.F. and R.J.A.d.S.; supervision, F.A.O.F. and R.J.A.d.S.; project administration, C.M., J.C. and D.F. All authors have read and agreed to the published version of the manuscript.

Funding: This work was supported by the projects UIDB/00481/2020 and UIDP/00481/2020 (FCT) Fundação para a Ciência e a Tecnologia; and CENTRO-01-0145-FEDER-022083-Centro Portugal Regional Operational Programme (Centro2020), under the PORTUGAL 2020 Partnership Agreement, through the European Regional Development Fund.

Acknowledgments: The authors would like to thank SATC Faculty for the technical and financial support to carry out this work. Research under grant CEECIND/01192/2017 acknowledges the support given by Fundação para a Ciência e a Tecnologia (FCT).

Conflicts of Interest: The authors declare no conflict of interest.

\section{Abbreviations}

The following abbreviations are used in this manuscript:

CAD Computer-Aided Design

CAE Computer-Aided Engineering

$\mathrm{CNC}$ Computer Numerical Control

FE Finite Element

\section{References}

1. Sutherland, I.E. Sketchpad a Man-Machine Graphical Communication System. Simulation 1964, 2, R-3-R-20. [CrossRef]

2. Evans, M.; Pei, E.; Cheshire, D.; Graham, I. Digital sketching and haptic sketch modelling during product design and development. Int. J. Prod. Dev. 2015, 20, 239-263. [CrossRef]

3. Aldoy, N.; Evans, M. A Review of Digital Industrial and Product Design Methods in UK Higher Education. Des. J. 2011, 14, 343-368. [CrossRef]

4. Xue, D. Teaching CAD in Mechanical and Manufacturing Engineering Programs-An experience at University of Calgary. In Proceedings of the Canadian Design Engineering Network (CDEN) Conference, Kaninaskis, AB, Canada, 18-20 July 2005; Paper-No. 9.

5. Field, D. Education and training for CAD in the auto industry. Comput.-Aided Des. 2004, 36, 1431-1437. [CrossRef]

6. Ye, X.; Peng, W.; Chen, Z.; Cai, Y. Today's students, tomorrow's engineers: An industrial perspective on CAD education. Comput.-Aided Des. 2004, 36, 1451-1460. [CrossRef]

7. Peck, J.J. Keeping it Social: Engaging Students Online and in Class. Asian Soc. Sci. 2012, 8, 81-90. [CrossRef]

8. Fritzen, D.; Castelan, J. Classes of computer aided drawing and manufacturing in a contextualized environment. In Proceedings of the 2012 15th International Conference on Interactive Collaborative Learning (ICL), Villach, Austria, 26-28 September 2012. [CrossRef]

9. Ullah, A.M.M.S.; Harib, K.H. Tutorials for Integrating CAD/CAM in Engineering Curricula. Educ. Sci. 2018, 8, 151. [CrossRef]

10. Bravo, L.E.C.; Bermudez, G.M.T.; Molano, J.I.R. Design and Application of a Creative Strategy Based on the Method of Problem-Based Learning (PBL) in Engineering Students. In Learning Technology for Education Challenges; Communications in Computer and Information Science; Springer: Cham, Switzerland, 2018; Volume 870.

11. Garcia, R. Teaching CAD at the university: Specifically written or commercial software? Comput. Educ. 2007, 49, 763-780. [CrossRef]

12. Guo, Y.; Yang, L.; Chen, X.; Yang, L. An Engineering-Problem-Based Short Experiment Project on Finite Element Method for Undergraduate Students. Educ. Sci. 2020, 10, 45. [CrossRef]

13. Besterfield-Sacre, M.; Cox, M.F.; Borrego, M.; Beddoes, K.; Zhu, J. Changing Engineering Education: Views of U.S. Faculty, Chairs, and Deans. J. Eng. Educ. 2014, 103, 193-219. [CrossRef] 
14. Sierpinska, A.; Kilpatrick, J.; Balacheff, N.; Howson, A.G.; Sfard, A.; Steinbring, H. What is research in mathematics education, and what are its result. J. Res. Math. Educ. 1993, 24, 274-278. [CrossRef]

15. Du, Y.; Tian, Q.; Du, X.; He, K. CAD/CAM courses integration of theoretical teaching and practical trainning. Procedia-Soc. Behav. Sci. 2014, 116, 4297-4300.

16. Cavalcante Koike, C.M.C.; Viana, D.M.; Vidal, F.B. Mechanical engineering, computer science and art in interdisciplinary project-based learning projects. Int. J. Mech. Eng. Educ. 2018, 46, 83-94. [CrossRef]

17. Neves, R.G.; Teodoro, V.D. Enhancing Science and Mathematics Education with Computational Modelling. J. Math. Model. Appl. 2010, 1, 2-15.

(C) 2020 by the authors. Licensee MDPI, Basel, Switzerland. This article is an open access article distributed under the terms and conditions of the Creative Commons Attribution (CC BY) license (http:/ / creativecommons.org/licenses/by/4.0/). 